\title{
Obstetrics and Gynecology Milestones
}

Jessica L. Bienstock, MD, MPH, Chair, Laura Edgar, EdD, CAE, Rebecca

MCALISTER, MD, ON BEHALF OF THE OBSTETRICS AND GYNECOLOGY WORKING GROUP

\section{Introduction}

One of the key elements of the Accreditation Council for Graduate Medical Education's (ACGME) Next Accreditation System is to move accreditation from a focus on structure and process to an emphasis on educational outcomes. The goal of the educational Milestones is to "provide accountability for effectiveness of educational programs in producing outcomes." Experienced educators in each specialty have been asked to describe the observable developmental steps that lead from novice to expert in that field. The goal of the Obstetrics and Gynecology Milestone development project was to produce a set of demonstrable, competency-based, progressive developmental outcomes to be assessed for each obstetrics and gynecology resident and, aggregated to the program level, to be reported to the ACGME on a semiannual basis. The Obstetrics and Gynecology Residency Review Committee (RRC) will use the Milestone data to assess program effectiveness and provide feedback to the programs to facilitate improvements in curricula and potentially other aspects of the educational program. In addition, residents and their faculty mentors can use the Milestones to frame discussion of an individual resident's progress along the continuum of training and to facilitate early identification and remediation in cases where residents fail to progress.

\section{Milestone Development History}

The Obstetrics and Gynecology Milestones were developed in 2 phases. During the first phase, a group of leaders in obstetrics and gynecology education was nominated by the American Board of Obstetrics and Gynecology, the American Congress of Obstetricians and Gynecologists, and the ACGME. The ACGME charged this framing group (в о х) with the task of developing a document that would comprehensively describe the skills needed by an obstetrics and gynecology residency graduate to practice competently and safely. To carry out this charge, the group drew from key educational guidelines, such as the Council on Resident Education in Obstetrics and Gynecology's Educational Objectives, A Core Curriculum in Obstetrics and Gynecology, ${ }^{2}$

Corresponding author: Jessica L. Bienstock, MD, MPH, Johns Hopkins University School of Medicine, 600 North Wolfe Street, Phipps 280, Baltimore, MD 21287, jbienst@jhmi.edu

DOI: http://dx.doi.org/10.4300/JGME-06-0151-08
B o X Members of the Obstetrics and Gynecology Milestone Framing Group, Working Group, and Advisory Committee

\section{Obstetrics and Gynecology Milestone Framing Group}

Rebecca McAlister, MD, Washington University School of Medicine, Chair

Haywood L. Brown, MD, Duke University

Tamara T. Chao, MD, Multicare Regional Maternal-Fetal Medicine

Missy Fleming, PhD, Accreditation Council for Graduate Medical

Education (ACGME)

Diane Hartmann, MD, University of Rochester

Lisa Johnson, MBA, ACGME

Lee A. Learman, MD, PhD, Indiana University School of Medicine

Frank Ling, MD, Vanderbilt University and Meharry Medical College Rebecca Miller, MS, ACGME

Krista Reagan, MD, University of Minnesota Medical School Jeffrey M. Rothenberg, MD, Indiana University

Andrew Satin, MD, Johns Hopkins University

Howard Shaw, MD, Saint Raphael Healthcare System and Women's

and Children's Services at Yale New Haven Hospital

David Soper, MD, Medical University of South Carolina

Ronald C. Strickler, MD, Henry Ford Health System

Susan R. Swing, PhD, ACGME

\section{Obstetrics and Gynecology Milestone Working Group}

Jessica L. Bienstock, MD, MPH, Johns Hopkins University School of Medicine, Chair

Karen E. Adams, MD, Oregon Health and Science University

AnnaMarie Connolly, MD, University of North Carolina at Chapel Hill Laura Edgar, EdD, CAE, ACGME

Gary N. Frishman, MD, Women \& Infants Hospital, Brown University Alice R. Goepfert, MD, University of Alabama at Birmingham

Robert V. Higgins, MD, FACOG, FACS, Levine Cancer Institute-Carolinas Medical Center

Lee A. Learman, MD, PhD, Indiana University School of Medicine Rebecca McAlister, MD, Washington University School of Medicine Mary Joyce Turner, MJ, RHIA, ACGME

George Wendel, MD, American Board of Obstetrics and Gynecology and University of Texas Southwestern Medical Center

Christopher M. Zahn, MD, Uniformed Services University of the Health Sciences

\section{Obstetrics and Gynecology Milestone Advisory Committee}

Timothy P. Brigham, MDiv, PhD

Mary Ciotti, MD

Larry C. Gilstrap III, MD

Hal C. Lawrence III, MD, FACOG

John R. Potts III, MD

the ACGME Program Requirements for Graduate Medical Education in Obstetrics and Gynecology, ${ }^{3}$ and the American Board of Obstetrics and Gynecology (ABOG) bulletins., ${ }^{4,5}$ The resulting Milestone document was all-inclusive and quite lengthy. Pilot testing found it to be thorough, yet challenging for busy program directors and the faculty to use, and a second committee (working group; B O X) was formed to reformat the Milestone document with the goal of producing a shorter and 
more user-friendly set of Milestones that would still measure resident accomplishments in each major area of obstetrics and gynecology practice.

Most of the new committee members were program directors whose programs had been pilot-test sites for the initial Milestones. While retaining the concept of describing the skills necessary for safe and independent practice of obstetrics and gynecology, the committee took a "biopsy" approach for the revised Milestones, which meant they chose several key required skills and assessed the development of the needed knowledge, attitudes, and skills along the continuum of resident education. As obstetrics and gynecology is a procedural-based specialty, the committee included both the index procedures that are currently monitored by the RRC and the developmental steps that lead to mastery of these procedures. Additionally, many Milestones reflect the development of competency in necessary skills, such as teamwork, patient advocacy, communication, quality improvement, professionalism, patient safety, and lifelong learning. The committee acknowledged that the revised Milestones do not describe the entirety of obstetrics and gynecology but emphasized that if residents are making appropriate progress in the areas assessed by the Milestones, it is highly likely that they will also be progressing satisfactorily in other key components of training.

\section{General Features of the Specialty Milestones}

The 28 Obstetrics and Gynecology Milestone sets (a set of Milestones reflects progressive levels of attainment of competence in a particular area) encompass the 6 ACGME competencies. The 18 Milestone sets for patient care and medical knowledge adhere to the structure of the ABOG oral examination format that graduates will soon take. The Milestone sets represent the areas of obstetrics (5 sets), gynecology ( 9 sets), and office practice (4 sets). Ten Milestone sets address the additional competencies of practice-based learning and improvement, professionalism, interpersonal and communication skills, and systems-based practice.

Each Milestone set progresses from knowledge of a topic to ability to manage straightforward presentations of a clinical problem to ability to manage complicated situations. Level 1 describes an entry-level resident. Level 2 describes a resident who has advanced to managing basic problems. Level 3 describes the more advanced skills expected of a midresidency trainee. Level 4 describes the knowledge, attitudes, and skills of a graduate who is ready to sit for examination by the ABOG. Level 5 describes activities and skills that would usually be beyond the level of accomplishment of most graduating residents but that may ultimately be demonstrated by individual physicians with special interest in that area. Importantly, the committee did not tie Milestone levels to a specific timeline or year of training. This decision reflects the wide range during which specific procedures and skills are taught at various programs. Thus, each level does not refer to a postgraduate year or year in the program, and there is no prescribed speed at which residents must progress through a Milestone set. It is anticipated that residents must have a certain amount of time in training to be challenged with more advanced problems. The expectation is that by the end of training graduates will have substantially demonstrated the Milestones leading up to and including Level 4 Milestones.

\section{Establishing Milestone Validity, Utility, and Practicality}

The validity, utility, and practicality of each version of the Obstetrics and Gynecology Milestones underwent pilot testing by the Council on Resident Education in Obstetrics and Gynecology of the American Congress of Obstetricians and Gynecologists. The initial pilot test was performed in November and December 2012, and 21 obstetrics and gynecology programs (15 university-based programs, 6 community-based programs) volunteered and participated in the initial pilot test and provided feedback to the committee via an anonymous survey. Each program formed a Clinical Competency Committee (CCC) and used the Milestone document to evaluate 1 or 2 residents at each postgraduate level (4 to 8 residents per program). Overall, programs reported that the Milestones were comprehensive and understandable and would enhance the resident educational program. However, the formatting of the original Milestone document and the time it required for completion were problematic.

Based on the information learned from the initial pilot test, the Milestones were revised and underwent a second round of pilot testing in 21 residency training programs. More than $90 \%$ of the CCCs and program directors piloting the revised Milestones found them to be easy to understand and representative of realistic progression of resident growth. The revised Milestones still require an average of 35 minutes to assess each resident. However, it is anticipated that as CCCs and program directors become more accustomed to using the Milestones and develop shared mental models of competence, the time to complete the Milestone assessments will shorten.

\section{Envisioned Practical Use in Evaluating Residents}

The Obstetrics and Gynecology RRC will continue to require each resident to undergo a semiannual evaluation that includes each resident's progress along the continuum 
of the Milestone sets. The Milestone assessments will help residents and their faculty mentors by providing more robust formative feedback and giving trainees specific examples of the skills they are expected to demonstrate. In addition to individual resident assessment, the program director and faculty should review aggregate data of resident performance and use this information to modify the curriculum to address any program-wide deficiencies. The next challenge for the obstetrics and gynecology community is to develop evaluation tools designed to inform each of the Milestones.

\section{Recommendations for Competency Committee Composition and Function}

To conduct the Milestone assessments for each resident, the program director will appoint a CCC that must be composed of at least 3 members of the core faculty, and each major participating site should be represented. Although it is not mandatory that the program director serve on the CCC, its work will be better informed by the program director's active participation. It is envisioned that the CCC will meet semiannually to review resident evaluations, examination results, case logs, surgical performance, and data from other evaluation tools. These will then inform the assessment of each resident's progress along the Milestone continuum. The CCC will also be responsible for preparing and reporting aggregated Milestone data to the ACGME. Finally, the CCC will function as an advisory board to the program director regarding resident progress and learning needs of the resident body as a whole.

\section{Conclusion}

The goal of the educational Milestones is to ensure that each graduate from an ACGME-accredited program receives the educational experiences needed to safely and independently practice in their specialty upon graduation. In describing the skills needed by obstetrics and gynecology graduates, the Milestones provide a means for measureable assessment of how well programs are preparing their graduates. As each resident will be able to clearly see their progress along the training continuum the Milestones describe, each program will be able to perform continuous quality improvement of its curriculum as it is compared to national standards. Through such accountability, we hope to, as Thomas J. Nasca, MD, MACP, described, ensure "the safety and quality of care of patients under the care of residents today ... [and] under the care of our graduates in their future practice."

\section{References}

1 Accreditation Council for Graduate Medical Education. The Next Accreditation System, June, 2012, Thomas J. Nasca, MD, MACP. http://www. acgme-nas.org/assets/pdf/Nasca\%2ONAS\%2OJune\%2O2012\% 20Presentation\%20Slide\%20Show.pdf. Accessed September 25, 2013.

2 American Congress of Obstetricians and Gynecologists. Educational Objectives, A Core Curriculum in Obstetrics and Gynecology, 10th Edition. http://www.acog.org/ /media/Departments/Members\%2OOnly/CREOG/ CREOGEducationalObjectives.pdf?dmc=1. Accessed September 25, 2013.

3 Accreditation Council for Graduate Medical Education. ACGME Program Requirements for Graduate Medical Education in Obstetrics and Gynecology. 2008. http://acgme.org/acgmeweb/Portals/o/PFAssets/ ProgramRequirements/220obstetricsandgynecology01012008.pdf. Accessed September 25, 2013

4 American Board of Obstetrics and Gynecology. 2014 Bulletin for the Written Examination for Basic Certification in Obstetrics and Gynecology. http://abog org/bulletins/current/basic.written.bulletin.pdf. Accessed September 25, 2013.

5 American Board of Obstetrics and Gynecology. 2014 Bulletin for the Oral Examination for Basic Certification in Obstetrics and Gynecology. http://abog. org/bulletins/current/basic.oral.bulletin.pdf. Accessed September 25, 2013 